\title{
A longitudinal study of psychosocial adjustment and community reintegration among former child soldiers in Sierra Leone
}

\author{
Theresa S. Betancourt ScD MA
}

Assistant Professor of Child Health and Human Rights, Department of Global Health and Population, Harvard School of Public Health, Boston, Massachusetts, USA, email Theresa_Betancourt@harvard.edu

\begin{abstract}
The forceful conscription of children (both boys and girls) into armed forces has been documented in at least 86 countries (Coalition to Stop the Use of Child Soldiers, 2008). Research suggests that these children may be at heightened risk of psychological and social problems (Wessells, 2009; Blattman \& Annan, 2010). However, there is little information on the long-term effects of child soldiers' wartime experiences.

In 2002, a collaboration between the Harvard School of Public Health and the International Rescue Committee (IRC) led to the launch of a longitudinal study of war-affected youth in Sierra Leone. The study was designed to identify risk and protective factors in psychosocial adjustment and social reintegration. The research was informed by an ecological approach to child health and well-being (Bronfenbrenner, 1979) and examined the interaction of influences at the individual, family, peer, community and cultural/collective levels (Betancourt \& Khan, 2008).
\end{abstract}

\section{Methods}

Survey interviews were conducted in 2002, 2004 and 2008. Participants were children who had been involved with the Revolutionary United Front and had later been referred to the IRC's disarmament, demobilisation and reintegration programme in Sierra Leone's Kono District. The sample was drawn from a master list of all youth who were served by the IRC's Interim Care Centre (ICC), which supported the reintegration of former child soldiers across five of Sierra Leone's 14 districts during the most active period of demobilisation (June 2001 to February 2002). We reviewed this list of 309 youth to identify those who were 10-17 years of age at the time of release from rebel groups and who had current contact information. In total, 260 youth (and their carers) agreed to participate in the baseline assessment.

All participants were interviewed (one to one) by trained Sierra Leonean research assistants, who verbally administered all study protocols in Krio, the most widely spoken language in Sierra Leone. The surveys contained a mix of standard measures and locally derived measures developed in close consultation with local staff and community members. Main measures of interest included information about age and length of involvement with armed groups, exposure to war-related violence and scores on a standardised scale of psychosocial adjustment developed and validated for use among former child soldiers in Sierra Leone by researchers at the Oxford Refugee Studies
Programme (MacMullin \& Loughry, 2004), which contained subscales for anxiety, depression, hostility, confidence and prosocial behaviour. The survey also included questions about family configuration and relationships upon return, community acceptance, social support, access to education and skills training and family socio-economic status. The 2004 and 2008 follow-up surveys repeated these baseline measures and added items to examine social capital, stigma/discrimination, high-risk behaviour, civic participation and post-conflict hardships.

In 2004, the team was able to re-interview $56.5 \%$ of the original survey sample, before data collection was terminated due to the death of the IRC's country director in a helicopter crash. In 2008, the team re-interviewed $68.8 \%$ of the original sample (this included some who were not re-interviewed in 2004). The 2004 data included over 30 in-depth qualitative interviews with former child soldiers (several of which also had a matching carer interview), as well as several focus groups with young people, carers and community members in major resettlement communities. In 2008-09, focus groups were again conducted, along with repeat interviews of a majority of previous informants. The team also conducted a series of key informant interviews with service providers and focus groups with war-affected youth of all backgrounds to examine opportunities and risks facing all war-affected youth in the post-conflict environment.

\section{Results}

This research has led to several publications about how warrelated and post-conflict experiences affect the long-term mental health and psychosocial adjustment of former child soldiers (Betancourt et al, 2008, 2010a-d). The research indicates that the long-term mental health of former child soldiers is affected both by war experiences and by postconflict factors. For instance, decreases in prosocial behaviour (such as helpfulness towards others) were associated with having killed or injured others during wartime, and with social stigmatisation of that child after the war. Young people who reported having been raped exhibited heightened anxiety and depression after the war. Worsening anxiety and depression over time were closely related both to younger age when first involved in fighting forces and to post-conflict social and economic hardship.

We looked at the role of stigma (including discrimination and lower levels of community and family acceptance) as a potential mediator between war-related experiences and 
problems with post-conflict psychosocial adjustment and adaptive behaviour. We found that societal stigmatisation of former child soldiers explained a significant proportion of the variance in levels of hostility that the cohort reported over time (Betancourt et al, 2010a); greater stigma was also associated with less prosocial behaviour.

These problems were partly mitigated by some post-conflict factors, including social support, being in school and increases in community acceptance over time. Higher levels of family acceptance were associated with lower hostility (Betancourt et al, 2010b). Improvement in community acceptance was associated with positive adaptive attitudes and behaviours. Overall, community acceptance - both initially and over time - had a beneficial effect on all outcomes studied. Our qualitative data also indicated that even young people who experienced extreme trauma could reintegrate well if they had strong family and community support. We also found that youth who lacked strong, effective support were on a much riskier path, characterised by social isolation and high-risk behaviour such as substance misuse and, in some cases, engaging in high-risk or abusive relationships in order to secure basic needs.

It was evident that psychosocial adjustment and community reintegration for former child soldiers are complex processes involving a range of factors both during and after wartime. However, post-conflict factors that play a role in determining long-term outcomes are of particular interest to researchers, practitioners and policy makers, since many of these can be modified, while war experiences cannot.

\section{Implications for policy and practice}

Efforts to assist former child soldiers at the end of the war did not translate into sustainable systems of social services and mental healthcare. Consequently, few social or mental health services for war-affected youth now remain, and the strengths and resources of individuals, families and communities are not maximised. New policy efforts are critically important in addressing these issues in Sierra Leone and elsewhere. Two policy developments which occurred 5 years after the start of the study are of particular importance: the publication by the Inter-Agency Standing Committee of its guidelines Mental Health and Psychosocial Support in Emergency Settings (see http://www.humanitarianinfo. org/iasc) and the Paris Principles and Guidelines on Children Associated with Armed Forces or Armed Groups (see http:// www.un.org/children/conflict/english/parisprinciples.html). Along with these documents, findings from this research and lessons learned from Sierra Leone can be applied to improving future disarmament, demobilisation and reintegration processes and the situation for war-affected youth.

First, targeting mental health and social services on selected groups of individuals based on 'labels' (e.g. having been a 'child soldier') may lead to an increase in societal stigma and further divisions within a community. War and its lingering consequences broadly affect a population and, as our qualitative data emphasised, 'no one's hands were clean' in the Sierra Leone conflict. Many individuals who were not involved in the Revolutionary United Front still participated in violence through the activities of the Sierra Leone Army or involvement in civilian defence forces. In fact, when comparisons were made between former child soldiers and other war-affected youth, few differences were observed in mental health outcomes or, apart from the unique effects of stigma directed at former child soldiers, in the operation of risk and protective factors on mental health outcomes over time. Such findings remind us that services should broadly serve all affected youth and should not contribute to stigma by singling out select groups for services driven by labels. Instead, services should target those most in need based on assessments of current distress and impairment.

All Sierra Leoneans can benefit from efforts both to build local capacity and to develop broadly based systems of mental health and social services. Sustainable national and community-level systems are needed that respond to the social service needs of all war-affected youth and families who experience ongoing difficulties.

At the same time, some youth may require long-term monitoring, assessment and follow-up for residual trauma or ongoing problems in the post-conflict environment. Such services should include specialised interventions such as drug and alcohol treatment, and community mediation for youth who continue to face stigma and poor community relations. Mental healthcare should cover health promotion and prevention services, social work and community-based mental health services, as well as clinical care for individuals with chronic mental illness, including out-patient and inpatient psychiatric treatment and medication management. To be successful, these services should have strong government leadership as well as linkages to community-based organisations, child welfare committees, job skills training programmes and educational and primary care systems.

Family and community acceptance plays an enormous role in positive mental health outcomes for war-affected youth in general, and former child soldiers in particular. Youth may promote their own reintegration into their families and communities through prosocial behaviour. Yet efforts must be made to present them with opportunities for education and personal development. Targeted interventions should maximise their adaptive strengths and support their capacity to reintegrate, by enhancing coping strategies and building skills for positive personal relationships.

Along with family and community acceptance, access to education plays a significant role in positive mental health outcomes. Education has the capacity to improve people's social standing and acceptance within a community, as well as to equip them for future economic and social stability. Because many war-affected youth experience extreme interruptions in schooling, interventions are needed that ensure educational access for all, including 'overgrown youth' and youth who have missed many years of school.

\section{Conclusions}

This research provides new insights into the long-term wellbeing of child soldiers. Both war experiences and post-conflict risk and protective factors affect the mental health and social reintegration of former child soldiers. Interventions should be long-term and sustainable, and focus on strengthening family and community support. Mental health services should be closely linked to education, primary healthcare and social development. Their provision should be based on need rather 
than labels, in order to benefit all war-affected youth and families. Services must also adapt to the evolving needs of individuals and families, as the mental health needs of waraffected youth change throughout the life course. Through this study and further developmentally informed scholarship, we can enhance our understanding of processes linking war-related traumas to long-term psychological functioning. Research is important to encourage local governments and the international community to invest in effective and sustainable responses to support the mental health needs of all war-affected children and families.

\section{References}

Betancourt, T. S. \& K. T. Khan (2008) The mental health of children affected by armed conflict: protective processes and pathways to resilience. International Review of Psychiatry, 20, 317-328.

Betancourt, T. S., Simmons, S., Borisova, I., et al (2008) High hopes, grim reality: reintegration and the education of former child soldiers in Sierra Leone. Comparative Education Review, 52, 565-587.

Betancourt, T. S., Agnew-Blais, J., Gilman, S. E., et al (2010a) Past horrors, present struggles: the role of stigma in the association between war experiences and psychosocial adjustment among former child soldiers in Sierra Leone. Social Science and Medicine, 70, 17-26.

Betancourt, T. S., Borisova, I. I., Williams, T. P., et al (2010b) Sierra Leone's former child soldiers: a follow-up study of psychosocial adjustment and community reintegration. Child Development, in press

Betancourt, T. S., Brennan, R. T., Rubin-Smith, J., et al (2010c) Sierra Leone's former child soldiers: a longitudinal study of risk, protective factors, and mental health. Journal of the American Academy of Child and Adolescent Psychiatry, 49, 606-615.

Betancourt, T. S., Zaeh, S. E., Ettien, A., et al (2010d) Psychosocial Adjustment and Mental Health Services in Post-conflict Sierra Leone: Experiences of CAAFAG and War-Affected Youth, Families and Service Providers (New Series on Transitional Justice). Intersentia (in press).

Blattman, C. \& Annan, J. (2010) The consequences of child soldiering. Review of Economics and Statistics, in press.

Bronfenbrenner, U. (1979) The Ecology of Human Development: Experiments by Nature and Design. Harvard University Press.

Coalition to Stop the Use of Child Soldiers (2008) Child Soldiers: Global Report 2008. Coalition to Stop the Use of Child Soldiers

MacMullin, C. \& Loughry, M. (2004) Investigating psychosocial adjustment of former child soldiers in Sierra Leone and Uganda. Journal of Refugee Studies, 17, 460-472.

Wessells, M. (2009) Supporting the mental health and psychosocial wellbeing of former child soldiers. Journal of the American Academy of Child and Adolescent Psychiatry, 48, 587-590.

\title{
Mental health in Hong Kong: transition from hospital-based service to personalised care
}

\author{
Eric F. C. Cheung, ${ }^{1}$ Linda C. W. Lam ${ }^{2}$ and Se-fong Hung ${ }^{3}$ \\ ${ }^{1}$ Consultant Psychiatrist, Castle Peak Hospital, Hong Kong Special Administrative Region, China; \\ 2Professor, Department of Psychiatry, The Chinese University of Hong Kong, Hong Kong Special Administrative Region, China; \\ ${ }^{3}$ Hospital Chief Executive, Kwai Chung Hospital, Hong Kong Special Administrative Region, China, email hungsf@ha.org.hk
}

$\mathrm{H}$ ong Kong was a UK colony before 1997 but has since been a Special Administrative Region of the People's Republic of China. It is located in southern China and has an area of $1104 \mathrm{~km}^{2}$. Approximately 95\% of Hong Kong's population is ethnic Chinese. Hong Kong is a developed capitalist economy, with a gross domestic product of US $\$ 301.6$ billion (2009 estimate), of which about $5.5 \%$ is spent on healthcare and about $0.24 \%$ on mental health (World Health Organization, 2005). Despite the relatively low level of spending on healthcare, Hong Kong nevertheless has one of the longest life expectancies in the world (79.2 years for men; 84.8 years for women) and a very low infant mortality rate (2.93 per 1000 live births) (Central Intelligence Agency, 2010).

\section{Mental health policy and legislation}

There is no specific mental health policy in Hong Kong. Instead, mental health services are subsumed within the overall health service of the territory, which is directed at the Hong Kong government level by the Food and Health Bureau. The lack of a coherent mental health policy has resulted in a lack of coordination between the medical sector, which provides assessment and treatment of mental disorders, and the social sector, which provides rehabilitation and ensures reintegration and support for people recovering from mental disorders (Hong Kong College of Psychiatrists, 2007).

On the other hand, a specific mental health ordinance was enacted in Hong Kong as early as 1906, in the form of the Asylums Ordinance, which underwent several major revisions and amendment in 1950, 1960, 1988 and 1997 (Lo, 1988; Cheung, 2000), during which process it became the Mental Health Ordinance of Hong Kong, largely based on the UK Mental Health Act 1983. In its current form, this ordinance contains provisions for: the management of the property and affairs of mentally incapacitated persons; the reception, detention and treatment of patients; guardianship; the admission of persons with a mental disorder who are involved in criminal proceedings; mental health review tribunals; and issues related to consent for medical and dental treatment for persons who are mentally incapacitated. 